\title{
BOUNDEDNESS AND CONTINUITY OF THE MILD SOLUTIONS OF SEMILINEAR STOCHASTIC FUNCTIONAL EVOLUTION EQUATIONS
}

\author{
RUHOLLAH JAHANIPUR
}

\begin{abstract}
In this paper, we study the boundedness and stability with respect to the parameters for the mild solutions of stochastic functional evolution equations in which the nonlinearity satisfies a monotone type condition. Our main tool is a version of the Itô-type inequality by means of which we can obtain an appropriate bound for $p$-th moment, $p \geqslant 2$, of the mild solutions.
\end{abstract}

Mathematics subject classification (2010): 34K50, 34C11, 60H15.

Keywords and phrases: Itô-type inequality, demicontinuous, semimonotone, functional evolution equation, mild solution, boundedness, continuity with respect to the parameters.

\section{REFERENCES}

[1] F. E. BRowDER, Nonlinear equations of evolution, Annals of Math. 80 (1964), 485-523.

[2] F. E. BRowder, Nonlinear initial value problems, Annals of Math. 81 (1965), 51-87.

[3] E. A. Coddington \& N. Levinson, Theory of ordinary differential equations, McGraw-Hill, 1955.

[4] R. F. CURTAIN \& A. J. PRITCHARD, Infinite dimensional linear system theory, Control and Information Sciences (8), Springer-Verlag, New York, Berlin, 1978.

[5] G. DA PRATO \& J. ZABCZYK, A note on semilinear stochastic equations, Differential and Integral Equations 1 (1988), 1-13.

[6] G. DA PRATO \& J. ZABCZYK, Stochastic equations in infinite dimensions, Cambridge, 1992.

[7] M. EMERY, Stabilité des solutions de équations différentielles stochastiques. Applications aux multiplicatives stochastiques, Z. W. 41 (1978), 241-262.

[8] W. G. FARIS \& G. JONA-LASINIO, Large fluctuations for a nonlinear heat equation with noise, J. Phys A: Math. Gen. 15 (1982), 3025-3055.

[9] W. E. Fitzgibbon, Semilinear functional differential equations in Banach space, J. Diff. Eqe. 29 (1978), 1-14.

[10] J. HALE, Theory of functional differential equations, Springer-Verlag, New York, 1977.

[11] A. ICHIKAWA, Semilinear stochastic evolution equations: boundedness, stability and invariant measures, Stochastics and Stochastic Reports 12 (1984), 1-39.

[12] R. JAhANiPUR \& B. Z. ZANGENEH, Stability of semilinear stochastic evolution equations with monotone nonlinearity, Math. Ineq. Appl. 3 (2000), 593-614.

[13] R. JAHANIPUR, Stability of stochastic delay evolution equations with monotone nonlinearity, Stochastic Anal. Appl. 21 (2003), 161-181.

[14] R. JAHANIPUR, Nonlinear functional differential equations of monotone-type in Hilbert spaces, Nonlinear Analysis: Theory, Methods and Applications 72 (2010), 1393-1408.

[15] R. JAHANIPUR, Stochastic functional evolution equations with monotone nonlinearity: existence and stability of the mild solutions, J. Differential Equations 248 (2010), 1230-1255.

[16] T. KATO, Integration of the equations of evolution in a Banach space, J. Math. Soc. Japan 5 (1953), 208-334.

[17] E. MÉTIVIER, Intégrales stochastiques Hilbertiennes, Cahier de Mathématiques de la Décision, 7617, Université Paris-Dauphiné, 1976.

[18] A. PAZY, Semigroups of linear operators and applications to partial differential equations, Applied Mathematical Sciences (44), Springer-Verlag, Berlin, 1983.

[19] H. TANabe, Equations of evolution, Pitman, London, 1979. 
[20] M. VAINBERG, Variational method and method of monotone operator in the theory of nonlinear equations, John Wiley \& Sons, 1973.

[21] M. YoR, Existence et unicité de diffusions à valeurs dans un espace de Hilbert, Annals Inst. H. Poincaré 10 (1974), 55-88.

[22] B. Z. ZANGeneh, Semilinear stochastic evolution equations, Ph.D thesis, University of British Columbia, Vancouver, B. C. Canada, 1990.

[23] B. Z. ZANGENEH, Semilinear stochastic evolution equations with monotone nonlinearities, Stochastics and Stochastic Reports 53 (1995), 129-174. 